\title{
Laparoscopic Sleeve Gastrectomy Using 42-French Versus 32-French Bougie
}

\author{
Jesse D. Beumer • Jonathan Shenfine
}

Published online: 1 May 2014

(C) Springer Science+Business Media New York 2014

To the Editor:

The identification of an ideal bougie size for sleeve gastrectomy is an important issue to balance the risk of reflux and leak involved with a smaller sleeve, compared to the risk of sleeve dilation, loss of restrictive effect and potentially compromised long-term weight loss associated with a larger calibrated sleeve. It was therefore with great anticipation that we approached the study by Spivak et al. [1] published in Obesity Surgery that compared the use of $42 \mathrm{Fr}$ to $32 \mathrm{Fr}$ bougie in laparoscopic sleeve gastrectomy. Unfortunately, the study design was inadequate to offer any new insights to the debate. By retrospectively selecting a small cohort, the study was never going to be adequately powered to reveal any difference in an acceptable leak rate of approximately $1 \%$ [2]. Equally, with a follow-up period of only 1 year, any difference related to sleeve dilatation, loss of restriction and subsequent difference to sustained weight loss would not be identified.

Although the study does consolidate our understanding of safety and efficacy associated with laparoscopic sleeve gastrectomy in the short term, we would encourage the authors to pursue investigation into ideal bougie size by drawing on their

stated experience and identify those subjects with longer follow-up. This could form a useful prelude to a larger, prospective, randomised study with more specific outcome measures and longer follow-up.

Jesse Beumer, MBBS, MSSc

Jonathan Shenfine, MBBS, PhD, FRCS

Professorial and Oesophago-Gastric Unit

Royal Adelaide Hospital

Australia

Conflict of Interest No conflict of interest to declare.

\section{References}

1. Spivak H, Moshe R, Sadot E, et al. Laparoscopic sleeve gastrectomy using 42-French versus 32-French bougie: the first-year outcome. Obes Surg. 2014 Mar. [Epub ahead of print]. PMID: 24577879

2. Rosenthal RJ, International Sleeve Gastrectomy Expert Panel. International Sleeve Gastrectomy Expert Panel consensus statement: best practice guidelines based on experience of $>12,000$ cases. Surg Obes Relat Dis. 2012;8(1):8-19.
J. D. Beumer $(\bowtie) \cdot J$. Shenfine

Professorial and Oesophago-Gastric Unit, Royal Adelaide Hospital, North Terrace, Adelaide, South Australia 5000, Australia

e-mail: jdbeumer@gmail.com

J. Shenfine

Department of Surgery, The University of Adelaide, Adelaide, South

Australia, Australia 